\title{
Mechanical efficiency of stunned myocardium is modulated by increased afterload dependency
}

\author{
Dongsheng Fan, Loe Kie Soei, Loes M A Sassen, Rob Krams, and Pieter D Verdouw
}

\begin{abstract}
Objective: Oxygen consumption $\left(\mathrm{MVO}_{2}\right)$ of stunned myocardium is relatively high compared to, and poorly correlated with, systolic contractile function. The aim of this study was to investigate whether an increased afterload dependency, induced by the decreased contractility of the stunned myocardium, contributes to the large variability in the mechanical efficiency data. Methods: In 13 anaesthetised open thorax pigs undergoing two cycles of $10 \mathrm{~min}$ occlusion of left anterior descending coronary artery and 30 min reperfusion, segment shortening, the slope of end systolic pressure segment length relationship $\left(E_{e s}\right)$, external work (EW, derived from the area inside the left ventricular pressure segment length loop), the efficiency of energy conversion $\left(\mathrm{EET},=\mathrm{EW} / \mathrm{PLA} \times 100 \%\right.$, where PLA = total pressure-segment length area), mechanical efficiency $\left(\mathrm{EW} / \mathrm{MVO} \mathrm{O}_{2}\right)$, and their dependency on left ventricular end systolic pressure $\left(\mathrm{P}_{\mathrm{es}}\right)$ were determined before and after induction of stunning, and during subsequent inotropic stimulation with dobutamine ( 1 and $3 \mu \mathrm{g} \cdot \mathrm{kg}^{-1} \cdot \mathrm{min}^{-1}$ over $15 \mathrm{~min}$ ). Results: The stunning protocol not only caused significant decreases in segment shortening, external work, energy conversion efficiency, and $\mathrm{EW} / \mathrm{MVO}_{2}$ but also increased the afterload dependency of these variables. Before stunning an increase in $\mathrm{P}_{\mathrm{es}}$ from 100 to $160 \mathrm{~mm} \mathrm{Hg}$ decreased segment shortening from $18(\mathrm{SEM} 1) \%$ to $14(2) \%(\mathrm{P}>0.05)$ and increased external work from $206(18)$ to $254(32) \mathrm{mm} \mathrm{Hg} \cdot \mathrm{mm}(\mathrm{P}<0.05)$. After induction of stunning the same increase in $\mathrm{P}_{\mathrm{es}}$ caused a decrease in segment shortening from $9.5(1.8) \%$ to $-4.6(2.1) \%(\mathrm{P}<0.05)$ and in external work from $149(21)$ to $-11(10) \mathrm{mm} \mathrm{Hg} \cdot \mathrm{mm}(\mathrm{P}<0.05)$. The afterload dependency of the PLA was not altered by stunning, but the afterload dependency of energy conversion efficiency increased, since efficiency decreased from $67(3) \%$ to $59(5) \%$ as $\mathrm{P}_{\mathrm{cs}}$ was increased from 100 to $160 \mathrm{~mm} \mathrm{Hg}$ before stunning, but from $57(5)$ to $-7(5) \%$ after induction of stunning $(\mathrm{P}<0.05)$. Furthermore, the same increase in $\mathrm{P}_{\mathrm{e} \text {, }}$ resulted in an $8 \%$ decrease of $\mathrm{EW} / \mathrm{MVO}_{2}$ before stunning and $107 \%$ after induction of stunning. Infusion of dobutamine not only restored segment shortening, external work, energy conversion efficiency, and EW/MVO ${ }_{2}$ of the stunned myocardium, but also attenuated their afterload dependency to prestunning levels. Conclusions: Myocardial stunning increases the afterload dependency of segment shortening, external work, energy conversion efficiency, and mechanical efficiency, which can be attenuated by inotropic stimulation with dobutamine. However, the decrease in left ventricular end systolic pressure, which accompanies the induction of stunning, counteracts the decrease in these variables. These two mechanisms can explain most of the reported scatter in mechanical efficiency.

Cardiovascular Research 1995;29:428-437
\end{abstract}

$\mathrm{O}$ xygen consumption $\left(\mathrm{MVO}_{2}\right)$ of stunned myocardium is not only relatively high compared to the postischacmic function, but is also poorly corrclated to the degree of regional dysfunction, as assessed by segment shortening or wall thickening. ${ }^{1-5}$ Schaper et al ${ }^{3}$ have postulated that differences in species may be a major factor in explaining this poor relationship since in dogs a $50 \%$ decrease in segment shortening was accompanied by a $30 \%$ decrease in $\mathrm{MVO}_{2}$, while in pigs $\mathrm{MVO}_{2}$ of the stunned myocardium was unchanged, despite the complete loss of segment shortening. However, mechanical efficiency, defined as the ratio between regional external work (EW, estimated from the area inside the left ventricular pressure-segment length loop) and $\mathrm{MVO}_{2}$, has been shown not to be decreased in stunned porcine myocardium but significantly decreased in stunned canine myocardium. ${ }^{4}$ This apparent discrepancy suggests that factors other than species differences must also play a part.

For instance, left ventricular systolic pressure is a major determinant of oxygen demand ${ }^{6}$ and stunning-induced changes in left ventricular systolic pressure therefore affect postischaemic myocardial oxygen demand. External work incorporates both segment length and pressure development and accounts for the changes in left ventricular systolic pressure. Its response to changes in left ventricular pressure, however, depends on the contractile state and therefore might be different for stunned myocardium. Data on the afterload dependency of external work in stunned myocardium are lacking, however, Nozawa et $a l^{7}$ have shown that in normal myocardium the efficiency of energy conversion from total mechanical work (estimated from total pressure-volume area) to external work not only depends on afterload but also on the level of contractility. Furthermore, they also showed that in normal myocardium this afterload dependency of energy conversion efficiency decreased during inotropic stimulation. ${ }^{7}$ Using left ventricular pressuresegment length relationships, we have shown that in stunned myocardium, both the contractile state and energy conversion efficiency are decreased. ${ }^{4}$ We therefore hypothesised that in regionally stunned myocardium, because of its depressed contractile state, the afterload dependency of energy conversion efficiency should be increased. The first aim of this study was therefore to evaluate this hypothesis by determining the afterload dependency of energy conversion efficiency obtained from left ventricular pressuresegment length relationships before and after induction of stunning. Since energy conversion efficiency is determined by the ratio of external work over total mechanical work 


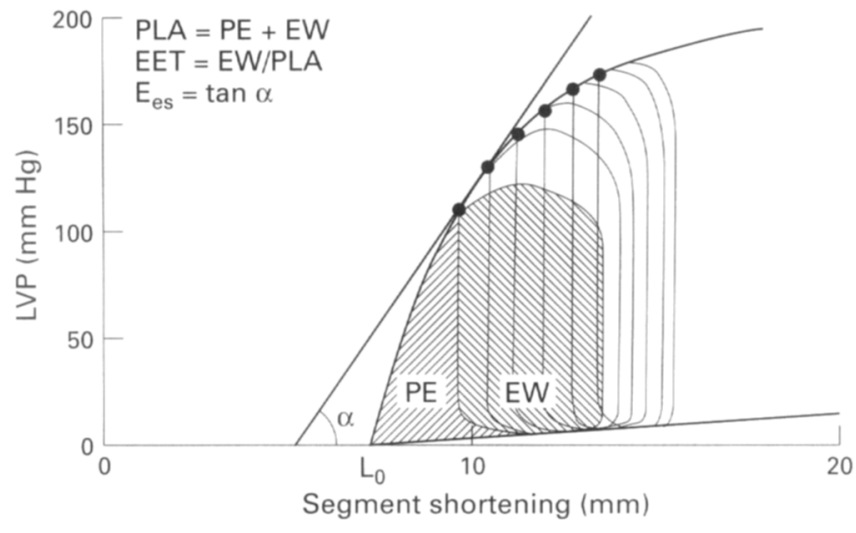

Figure 1 Definition of the indices for total mechanical work (PLA), potential energy (PE), external work (EW), efficiency of energy conversion (EET), and the slope of end systolic left ventricular pressure-segment length relationship $\left(E_{e s}\right) . L V P=$ left ventricular pressure; $L_{0}=$ segment length at zero pressure.

(fig 1), we also evaluated how the afterload dependency of external work and systolic shortening was affected by myocardial stunning.

Burkhoff and Sagawa ${ }^{8}$ have established a relationship between mechanical efficiency, contractile state, and afterload. This theoretical relationship implies that in normal myocardium mechanical efficiency becomes less afterload dependent when contractility increases. We therefore hypothesised that in stunned myocardium the afterload dependency of mechanical efficiency is increased. This information should enable us to evaluate the hypothesis that a stunning induced decrease in afterload can compensate for the decrease in mechanical efficiency induced by the decreased contractile state of stunned myocardium and thereby contribute to the reported variability of mechanical efficiency. ${ }^{1-5}$

\section{Methods}

All experiments were performed in accordance with the Guiding principles in the care and use of animals as approved by the Council of the American Physiological Society and under the regulations of the animal care committee of the Erasmus University Rotterdam.

After an overnight fast crossbred Yorkshire-Landrace pigs (25-30 kg, $\mathrm{n}=13$ ) were sedated with $20 \mathrm{mg} \cdot \mathrm{kg}^{-1}$ ketamine intramuscularly, anaesthetised with $20-30 \mathrm{mg} \cdot \mathrm{kg}^{-1}$ sodium pentobarbitone intravenously, intubated, and ventilated with a mixture of $\mathrm{O}_{2}$ and $\mathrm{N}_{2}(1: 2, \mathrm{vol} / \mathrm{vol})$, Arterial oxygen content and blood gases were kept within the normal range. ${ }^{4}$ Two $7 \mathrm{~F}$ catheters were placed in the superior caval vein for (1) infusion of 5-10 mg. $\mathrm{kg}^{-1} \cdot \mathrm{h}^{-1}$ sodium pentobarbitone, (2) administration of $4 \mathrm{mg}$ pancuronium bromide before thoractomy, and (3) infusion of either dobutamine or saline. Aortic blood pressure was monitored via an $8 \mathrm{~F}$ catheter in the thoracic descending aorta, while left ventricular pressure was obtained with a $7 \mathrm{~F}$ micromanometer tipped catheter (Braun).

Following a midline sternotomy, an electromagnetic flow probe (Skalar) was placed around the ascending aorta. A proximal scgment of the left anterior descending coronary artery was dissected free for positioning of an electromagnetic flow probe and the placement of an atraumatic clamp. The vein accompanying this arlery, which specifically drains the myocardium perfused by it, ${ }^{9}$ was cannulated for collection of coronary venous blood. The balloon of a 7F Fogarty catheter was then positioned underneath the flow probe around the aorta. Pacing leads were attached to the right atrial appendage and connected to a pacing stimulator. Rectal temperature was monitored throughout the experiment and maintained between 37 and $38^{\circ} \mathrm{C}$ using external heating pads and covering the animals with blankets.

Segment length changes were measured by sonomicrometry (Triton Technology) using two pairs of ultrasound crystals (Sonotek). One pair was positioned in the distribution area of the left anterior descending coronary artery, and the other pair in the distribution area of the left circumflex coronary artery. Care was taken to position the crystals in the mesocardial layers and perpendicular to the outflow tract of the left ventricle, thus parallel to the muscle fibre direction. ${ }^{10}$
Experimental protocol

After a $30-45$ min stabilisation period, baseline recordings were made of systemic haemodynamic variables, left anterior descending coronary artery blood flow, and segment length in the two myocardial regions, whilc arterial and coronary venous blood samples were collected for measurement of oxygen content. With the ventilation switched off, the balloon in the ascending aorta was then gradually inflated over a period of 5-10 s to create a series of 10-20 beats with increasing afterloads (40-50 $\mathrm{mm} \mathrm{Hg}$ increase in left ventricular end systolic pressure) for the construction of the left ventricular end systolic pressure-segment length relationships. The procedure is sufficiently short to prevent reflex mediated changes in contractility. " The left ventricular pressure and segment length signals were digitised and stored on disk for off-line analysis. ${ }^{4}$

After baseline data were recorded, heart rate was raised by 30 beats $\mathrm{min}^{-1}$ for $3 \mathrm{~min}$. After all variables were again determined heart rate was raised by another 30 beats. $\mathrm{min}^{-1}$ and 3 min later all measurements were repeated. The pacemaker was then switched off and following a short stabilisation period, the left anterior descending coronary artery was occluded twice for $10 \mathrm{~min}$ at $30 \mathrm{~min}$ intervals to induce stunning. ${ }^{2}$ Thirty minutes after the second occlusion, all data were again collected at intrinsic heart rate and after pacing induced increments of 30 and 60 beats $\cdot \mathrm{min}^{-1}$, respectively. The animals were then assigned arbitrarily to two groups. Seven animals were further studied after receiving consecutive $15 \mathrm{~min}$ infusions of dobutamine ( 1 and $3 \mu \mathrm{g} \cdot \mathrm{kg}^{-1} \cdot \mathrm{min}^{-1}$ ), while six animals were further studied after receiving identical volumes ( 1 and $2 \mathrm{ml} \cdot \mathrm{min}^{-1}$, respectively) of saline.

Data analysis and statistics

The ascending aortic blood flow was taken as the cardiac output, although it does not take into account the coronary blood flow, which may amount to $2-4 \%$ of the total output. Segment length was measured at end systole (ESL) and at end diastole (EDL) to calculate segment shortening as $(\mathrm{EDL}-\mathrm{ESL}) / \mathrm{EDL} \times 100 \%$. The end systolic pressuresegment length relationships were determined by fitting left ventricular end systolic pressure-segment length points to a second order regression equation. ${ }^{4}{ }^{13-16}$ In addition, the area inside the left ventricular pressuresegment length loop was determined as an index of the external work. ${ }^{5} 17$ Total mechanical work was determined by calculating the total pressure-length area (PLA) enclosed by end systolic and end diastolic pressure-segment length relationships and the systolic trajectory of the pressure-segment length loop ${ }^{4}$ and the efficiency of energy conversion as EW/PLA $\times 100 \%$. To correct for differences in end diastolic length at baseline, external work and pressure-length area were normalised to an end diastolic length of $10 \mathrm{~mm}$ at baseline.

The relationships between segment shortening, external work, total mechanical work, energy conversion efficiency, and left ventricular end systolic pressure $\left(\mathrm{P}_{\mathrm{er}}\right)$ were analysed using linear regression (Statgraphics). Curvilinearity of each relationship was calculated by a second order regression model. This second order model was considered to be superior over the linear model on the basis of two criteria: the coefficient of the quadratic term was different from zero $(\mathrm{P}<0.05)$ or the $\mathrm{F}$ statistic $\left[\left(\mathrm{SS}_{2}-\mathrm{SS}_{1}\right) \mathrm{MS}_{1}\right]$ reached statistical significance $(\mathrm{P}<0.05)$. In this expression $\mathrm{SS}$ is the sum of squares, MS is the mean sums of squares, while the subscripts 1 and 2 refer to the first and second order regression model, respectively.

In the four steady state conditions (baseline, stunning, and the subsequent two infusion rates of dohutamine or saline), oxygen consumption of the myocardium supplied by the left anterior descending coronary artery $\left(\mathrm{MVO}_{2}\right)$ was calculated as the product of myocardial blood flow and the difference in the arterial and local coronary venous oxygen contents. During the transient increases in afterload, the beat to beat changes in $\mathrm{MVO}_{2}$ were calculated using the equation $\mathrm{MVO}_{2}\left(\mathrm{P}_{\mathrm{es}}\right)=\alpha \mathrm{E}_{\mathrm{es}}\left(\mathrm{P}_{\mathrm{es}}\right)+\beta \mathrm{PLA}\left(\mathrm{P}_{\mathrm{es}}\right)+\gamma$, in which the dependency of $\mathrm{E}_{\mathrm{es}}$ and PLA on $\mathrm{P}_{\mathrm{es}}$ has been established above. The constants $\alpha, \beta$, and $\gamma$ are independent of heart rate and the afterload. ${ }^{68}$ but may be affected by the induction of stunning. At baseline and after induction of stunning, the constants can be calculated, however, using the values for $\mathrm{MVO}_{2}, \mathbf{E}_{\mathrm{ec}}$, and PLA obtained at the intrinsic heart rate and during the two pacing tests. Combining the data on $\mathrm{MVO}_{2}\left(\mathrm{P}_{\mathrm{er}}\right)$ with those of external work $\left(\mathrm{P}_{\mathrm{es}}\right)$ permits determination of the afterload dependency of mechanical efficiency (external work/ $/ \mathrm{MVO}_{2}$ ). Because heart rate increased during infusion of dobutamine, it was not possible to obtain a set of three equations with the same increments in heart rate under these conditions. For dobutamine we can therefore only provide the values of external work $/ \mathrm{MVO}_{2}$ during the steady state condition.

All data have been expressed as mean(SEM). Significance of the changes induced by the stunning protocol were evaluated using the Student's paired $t$ test (two tailed, $\mathbf{P}<0.05$ ). Significance of the effects of dobutamine and saline during myocardial stunning was assessed by two way analysis of variance with repeated measures and Bonferron adjustment (BMDP Statistical Software). Because the increases in $E_{\text {es }}$ in the left circumflex coronary area region were not normally distributed the non-parametric test was used to determine the statistical significance. 


\section{Results}

Systemic haemodynamics (table I)

The stunning protocol caused decreases $(\mathrm{P}<0.05)$ in left ventricular $\mathrm{dP} / \mathrm{dt}_{\max }$ [25(3)\%], cardiac output [15(3)\%], and an increase in systemic vascular resistance $[15(4) \%$, $\mathrm{P}<0.05]$. Heart rate remained unchanged and the decrease in cardiac output was therefore a consequence of a decrease in stroke volume [11(5)\%, P< $<.05]$. Infusion of saline after induction of stunning had no effect on any of these systemic haemodynamic variables. Infusion of dobutamine caused dose dependent increases $(\mathrm{P}<0.05)$ in heart rate $[23(5) \%]$, left ventricular $\mathrm{dP} / \mathrm{dt}_{\max }[125(22) \%]$, and cardiac output $[28(10) \%]$, and a decrease in systemic vascular resistance $[18(6) \%, \mathrm{P}<0.05]$.
Effect of dobutamine on contractile function of stunned and non-stunned myocardium (table II)

In the distribution area of the left anterior descending coronary artery, segment shortening decreased from 19.1(1.3)\% to $8.8(1.1) \%(\mathrm{P}<0.05)$ after induction of stunning. There were no further changes in segment shortening during the subsequent saline infusion, but during dobutamine infusion the mean value recovered dose dependently to $17.4(1.8) \%$. In the non-stunned myocardium segment shortening was not affected by either the induction of stunning or the saline or dobutamine infusions.

In the distribution area of the left anterior descending coronary artery, $\mathrm{E}_{\mathrm{es}}$ (at $100 \mathrm{~mm} \mathrm{Hg}$ ) was reduced to $60(7) \%$ of baseline after the two occlusion-reperfusion sequences, but returned to baseline during infusion of $3 \mu \mathrm{g} \cdot \mathrm{kg}^{-1} \cdot \mathrm{min}^{-1}$

Table I Systemic haemodynamic variables in pigs with stunned myocardium during infusion of saline or dobutamine. The myocardium was stunned by two periods of $10 \mathrm{~min}$ of left anterior descending coronary artery occlusion separated by 30 min of myocardial reperfusion. Values are means(SEM).

\begin{tabular}{|c|c|c|c|c|c|}
\hline & \multirow{2}{*}{$\begin{array}{l}\text { Baseline } \\
(n=13)\end{array}$} & \multirow{2}{*}{$\begin{array}{l}\text { Stunning } \\
(n=13)\end{array}$} & \multirow[b]{2}{*}{$\begin{array}{l}\text { Saline } n=6 \\
\text { Dobutamine } n=7\end{array}$} & \multicolumn{2}{|c|}{ Infusion rate } \\
\hline & & & & $I$ & $\begin{array}{l}2 \\
3\end{array}$ \\
\hline & & & & \multicolumn{2}{|c|}{$\Delta$ from stunning } \\
\hline Heart rate (beats $\min ^{-1}$ ) & $109(2)$ & $106(4)$ & $\begin{array}{l}\text { Saline } \\
\text { Dobutamine }\end{array}$ & $\begin{array}{l}0(8) \\
6(4) \dagger\end{array}$ & $\begin{array}{l}-2(8) \\
24(4) \dagger\end{array}$ \\
\hline Mean arterial pressure (mm $\mathrm{Hg}$ ) & $89(1)$ & $85(2)$ & $\begin{array}{l}\text { Saline } \\
\text { Dobutamine }\end{array}$ & $\begin{array}{l}0(1) \\
3(2)\end{array}$ & $\begin{array}{l}5(2) \\
2(2)\end{array}$ \\
\hline $\mathrm{LV} \mathrm{dP} / \mathrm{dt}_{\operatorname{mix}}\left(\mathrm{mm} \mathrm{Hg} \cdot \mathrm{s}^{-1}\right)$ & $2360(160)$ & $1770(130)^{*}$ & $\begin{array}{l}\text { Saline } \\
\text { Dobutamine }\end{array}$ & $\begin{array}{l}20(175) \\
855(130) \dagger\end{array}$ & $\begin{array}{l}65(160) \\
2240(190) \dagger\end{array}$ \\
\hline Cardiac output (litres-min ${ }^{-1}$ ) & $3.0(0.2)$ & $2.5(0.1)^{*}$ & $\begin{array}{l}\text { Saline } \\
\text { Dobutamine }\end{array}$ & $\begin{array}{l}0.0(0.2) \\
0.2(0.1)\end{array}$ & $\begin{array}{l}0.0(0.1) \\
0.6(0.2) \dagger\end{array}$ \\
\hline Systemic vascular resistance $\left(\mathrm{mm} \mathrm{Hg} \cdot \mathrm{litre}^{-1} \cdot \mathrm{min}\right)$ & $32(2)$ & $36(2)^{*}$ & $\begin{array}{l}\text { Saline } \\
\text { Dobutamine }\end{array}$ & $\begin{array}{r}0(3) \\
-3(2)\end{array}$ & $\begin{array}{l}1(3) \\
-6(1) \dagger\end{array}$ \\
\hline Stroke volume $(\mathrm{ml})$ & $27(2)$ & $23(1)^{*}$ & $\begin{array}{l}\text { Saline } \\
\text { Dobutamine }\end{array}$ & $\begin{array}{l}1(2) \\
1(2)\end{array}$ & $\begin{array}{l}1(1) \\
1(2)\end{array}$ \\
\hline Left ventricular end diastolic pressure $(\mathrm{mm} \mathrm{Hg}$ ) & $y(1)$ & $10(1)$ & $\begin{array}{l}\text { Saline } \\
\text { Dobutamine }\end{array}$ & $\begin{array}{l}-2(1) \\
-2(1)\end{array}$ & $\begin{array}{r}0(2) \\
-2(1)\end{array}$ \\
\hline
\end{tabular}

${ }^{\mathrm{a}} \mathrm{ml} \cdot \mathrm{min}^{-1}$ for saline and $\mu \mathrm{g} \cdot \mathrm{kg}^{-1} \cdot \mathrm{min}^{-1}$ for dobutamine; $\mathrm{LV} \mathrm{dP} / \mathrm{dt}_{\mathrm{max}}=$ maximum rate of rise of left ventricular pressure.

$* \mathrm{P}<0.05 v$ baseline (for stunning values only); fdobutamine induced change from stunning is significantly different $(\mathrm{P}<0.05)$ from saline induced change from stunning.

Table II Changes in regional contractile function in pigs with stunned (left anterior descending coronary artery supply) and non-stunned (left circumflex coronary artery supply) myocardium during infusion of saline or dobutamine. The myocardium was stunned by two periods of $10 \mathrm{~min}$ of left anterior descending coronary artery occlusion separated by $30 \mathrm{~min}$ of myocardial reperfusion. Values are means(SEM).

\begin{tabular}{|c|c|c|c|c|c|}
\hline & \multirow{2}{*}{$\begin{array}{l}\text { Baseline } \\
(n=13)\end{array}$} & \multirow{2}{*}{$\begin{array}{l}\text { Stunning } \\
(n=13)\end{array}$} & \multirow[b]{2}{*}{$\begin{array}{l}\text { Saline } n=6 \\
\text { Dobutamine } n=7\end{array}$} & \multicolumn{2}{|c|}{ Infusion rate $\mathrm{a}^{\mathrm{a}}$} \\
\hline & & & & $\begin{array}{l}I \\
I\end{array}$ & $\begin{array}{l}2 \\
3\end{array}$ \\
\hline & & & & $\Delta$ from stu & \\
\hline $\begin{array}{l}\text { Systolic segment shortening (\%) } \\
\text { LADCA }\end{array}$ & $19.1(1.3)$ & $8.8(1.1)^{*}$ & Saline & $0.6(1.7)$ & $1.0(2.1)$ \\
\hline LCXCA & $14.6(1.7)$ & $13.2(1.4)$ & $\begin{array}{l}\text { Saline } \\
\text { Dobutamine }\end{array}$ & $\begin{array}{r}-1.2(2.1) \\
3.3(1.9)\end{array}$ & $\begin{array}{r}-1.0(2.0) \\
3.3(2.2)\end{array}$ \\
\hline $\begin{array}{l}\mathrm{E}_{\mathrm{es}}\left(\mathrm{mm} \mathrm{Hg} \cdot \mathrm{mm}^{-1}\right) \\
\text { LADCA }\end{array}$ & $47(5)$ & $27(2)^{*}$ & $\begin{array}{l}\text { Saline } \\
\text { Dobutamine }\end{array}$ & $\begin{array}{l}-4(3) \\
-3(3)\end{array}$ & $\begin{array}{l}-1(2) \\
21(5) \dagger\end{array}$ \\
\hline $\mathrm{LCXCA}$ & $75(11)$ & $66(6)$ & $\begin{array}{l}\text { Saline } \\
\text { Dobutamine }\end{array}$ & $\begin{array}{c}0(6) \\
-4(10)\end{array}$ & $\begin{array}{l}\text { I(5) } \\
32(27) \dagger\end{array}$ \\
\hline $\begin{array}{l}\mathrm{L}_{\mathrm{o}}(\mathrm{mm}) \\
\quad \mathrm{LADCA}\end{array}$ & $6.7(0.5)$ & $7.2(0.5)$ & $\begin{array}{l}\text { Saline } \\
\text { Dobutamine }\end{array}$ & $\begin{array}{l}-0.3(1.2) \\
-1.4(1.1)\end{array}$ & $\begin{array}{r}-0.2(0.9) \\
0.2(0.8)\end{array}$ \\
\hline LCXCA & $7.6(0.6)$ & $7.7(0.4)$ & $\begin{array}{l}\text { Saline } \\
\text { Dobutamine }\end{array}$ & $\begin{array}{r}-0.1(0.5) \\
0.1(0.9)\end{array}$ & $\begin{array}{l}0(0.5) \\
0.7(0.8)\end{array}$ \\
\hline
\end{tabular}

${ }^{\mathrm{a}} \mathrm{ml} \cdot \mathrm{min}^{-1}$ for saline and $\mu \mathrm{g} \cdot \mathrm{kg}^{-1} \cdot \mathrm{min}^{-1}$ for dobutamine; LADCA = left anterior descending coronary artery; $L C X C A=$ left circumflex coronary artery; $\mathrm{E}_{\mathrm{rs}}=\mathrm{slope}$ of the left ventricular end systolic pressure-segment length relationship at $100 \mathrm{~mm} \mathrm{Hg} ; \mathrm{L}_{\mathrm{o}}=$ segment length at zero mm $\mathrm{Hg}$ left ventricular pressure.

$* \mathrm{P}<0.05 v$ baseline (for stunning values only); tdobutamine induced change from stunning is significantly different $(\mathrm{P}<0.05)$ from saline induced change from stunning. 
dobutamine. $E_{\mathrm{es}}$ of the non-stunned segment was not affected by the stunning protocol, but increased by more than $50 \%$ during infusion of dobutamine $(P<0.05)$. Neither stunning nor dobutamine infusion had any effect on the value of $L_{0}$ in either distribution area. Infusion of saline also had no effect on $E_{e s}$ and $L_{o}$ of the stunned and non-stunned myocardium, providing additional evidence for the stability of the preparation.

Effect of dobutamine on total mechanical work, external work, and energy conversion efficiency of stunned and non-stunned myocardium (table III)

Induction of stunning and the infusions of saline or dobutamine did not affect total mechanical work in the distribution areas of the left anterior descending and left circumflex coronary arteries. Although total mechanical work of the stunned region was not significantly affected by stunning, there was a redistribution in favour of the potential energy as the external work was reduced to $52(5) \%$ of baseline. There were no further changes in external work of the stunned myocardium during infusion of saline, but during infusion of dobutamine external work returned to baseline. In the non-stunned myocardium, external work increased $(P<0.05)$ during infusion of the highest dose of dobutamine, but the effect was less pronounced than in the stunned myocardium.

A consequence of the decrease in external work and the negligible effect of total mechanical work was that energy conversion efficiency of the stunned myocardium decreased from $69(4) \%$ to $45(4) \%(\mathrm{P}<0.05)$. During infusion of saline, there were no changes in energy conversion efficiency, but during infusion of dobutamine there was almost complete recovery. In the non-stunned myocardium energy conversion efficiency increased to $79(5) \%$ during infusion of the highest dose of dobutamine.

Effect of dobutamine on $\mathrm{MVO}_{2}$ and mechanical efficiency of stunned myocardium (fig 2, table III)

$\mathrm{MVO}_{2}$ decreased from $3.9(0.2)$ to $3.1(0.2) \mu \mathrm{mol} \cdot$ beat $^{-1} \cdot 100 \mathrm{~g}^{-1}$ $(\mathrm{P}<0.05)$ after induction of stunning, but the relative decrease

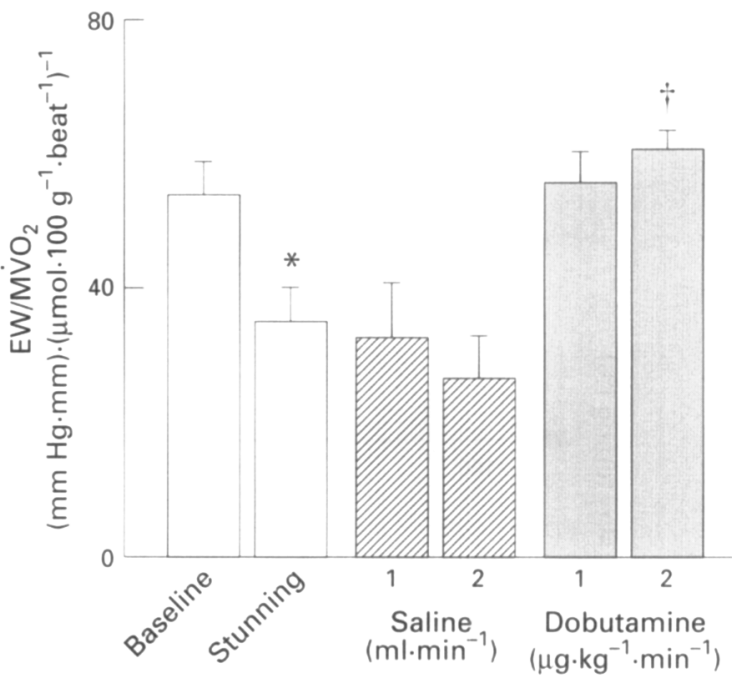

Figure 2 Effect of dobutamine on mechanical efficiency $\left(E W / M \mathrm{VO}_{2}\right)$ of stunned myocardium. EW = external work; $M \dot{V} \mathrm{O}_{2}=$ myocardial oxygen consumption. Values are means, error bars $=S E M$.

$* P<0.05 \vee$ baseline (for stunning only); $\dagger$ dobutamine induced change from stunning is significantly different $(P<0.05)$ from the saline induced change from stunning.

was less than the decrease in external work, implying a reduction in mechanical efficiency (external work to $\mathrm{MVO}_{2}$ ratio; EW/ $\mathrm{MVO}_{2}$ ) from $54(5)$ to $35(5) \mathrm{mm} \mathrm{Hg} \cdot \mathrm{min} \cdot\left(\mu \text { mol beat }{ }^{-1} \cdot 100 \mathrm{~g}^{-1}\right)^{-1}$ $(\mathrm{P}<0.05) . \quad \mathrm{MVO}_{2} \quad$ (per beat) remained unchanged during dobutamine infusion. In view of the increase in external work, this implied that $\mathrm{EW} / \mathrm{MV} \mathrm{O}_{2}$ increased.

\section{Afterload dependency of contractile function (fig 3)}

Before induction of stunning, segment shortening in the distribution area of the left anterior descending coronary artery was only minimally affected when $P_{c s}$ was increased, but after induction of stunning, it became very sensitive to increases in $P_{\mathrm{es}}$. This afterload dependency of segment shortening did not change during infusion of saline, but was

Table III Changes in total mechanical work, external work, and efficiency of energy conversion in pigs with stunned (left anterior descending coronary artery supply) and non-stunned (left circumflex coronary artery supply) myocardium during infusion of saline or dobutamine. The myocardium was stunned by two periods of $10 \mathrm{~min}$ of lefi anteriur descending coronary artery occlusion separated 30 min of myocardial reperfusion. Values are means(SEM).

\begin{tabular}{|c|c|c|c|c|c|}
\hline & \multirow{2}{*}{$\begin{array}{l}\text { Baseline } \\
(n=13)\end{array}$} & \multirow{2}{*}{$\begin{array}{l}\text { Stunning } \\
(n=13)\end{array}$} & \multirow[b]{2}{*}{$\begin{array}{l}\text { Saline } n=6 \\
\text { Dobutamine } n=7\end{array}$} & \multicolumn{2}{|c|}{ Infusion rate } \\
\hline & & & & $\begin{array}{l}l \\
l\end{array}$ & $\begin{array}{l}2 \\
3\end{array}$ \\
\hline & & & & \multicolumn{2}{|c|}{$\Delta$ from stunning } \\
\hline $\begin{array}{l}\text { PLA (mm Hg.mm) } \\
\text { LADCA }\end{array}$ & $292(17)$ & $240(23)$ & \multirow{2}{*}{$\begin{array}{l}\text { Saline } \\
\text { Dobutamine } \\
\text { Saline } \\
\text { Dobutamine }\end{array}$} & \multirow{2}{*}{$\begin{array}{c}-10(37) \\
100(39) \\
-14(20) \\
45(41)\end{array}$} & \multirow{2}{*}{$\begin{array}{c}50(32) \\
30(37) \\
-20(20) \\
0(31)\end{array}$} \\
\hline LCXCA & $245(29)$ & $218(26)$ & & & \\
\hline $\begin{array}{l}\text { External work }(\mathrm{mm} \mathrm{Hg} \cdot \mathrm{mm}) \\
\text { LADCA }\end{array}$ & 204(15) & $109(14)^{*}$ & \multirow{2}{*}{$\begin{array}{l}\text { Saline } \\
\text { Dobutamine } \\
\text { Saline } \\
\text { Dobutamine }\end{array}$} & \multirow{2}{*}{$\begin{array}{c}6(21) \\
60(17) \\
-7(13) \\
25(33)\end{array}$} & \multirow{2}{*}{$\begin{array}{c}10(25) \\
80(23) \dagger \\
-16(19) \\
50(27) \dagger\end{array}$} \\
\hline $\mathrm{LCXCA}$ & $168(17)$ & $144(17)$ & & & \\
\hline $\begin{array}{l}\text { Energy conversion efficiency (\%) } \\
\text { LADCA }\end{array}$ & $69(4)$ & $45(4)^{*}$ & $\begin{array}{l}\text { Saline } \\
\text { Dobutamine }\end{array}$ & $\begin{array}{l}2(9) \\
7(6)\end{array}$ & $\begin{array}{l}-1(6) \\
22(4)+\end{array}$ \\
\hline LCXCA & $65(2)$ & $65(3)$ & $\begin{array}{l}\text { Salinc } \\
\text { Dobutamine }\end{array}$ & $\begin{array}{l}0(8) \\
5(6)\end{array}$ & $\begin{array}{l}-4(8) \\
17(5) \dagger\end{array}$ \\
\hline
\end{tabular}

${ }^{a} \mathrm{ml} \cdot \mathrm{min}^{-1}$ for saline and $\mu \mathrm{g} \cdot \mathrm{kg}^{-1} \cdot \mathrm{min}^{-1}$ for dobutamine; LADCA $=$ left anterior descending coronary artery; LCXCA $=$ left circumflex coronary artery; PLA = total pressure segment length area. Energy conversion efficiency = external work/PLA.

$* \mathrm{P}<0.05 v$ baseline (for stunning values only). †dobutamine induced change from stunning is significantly different $(\mathrm{P}<0.05)$ from saline induced change from stunning. 

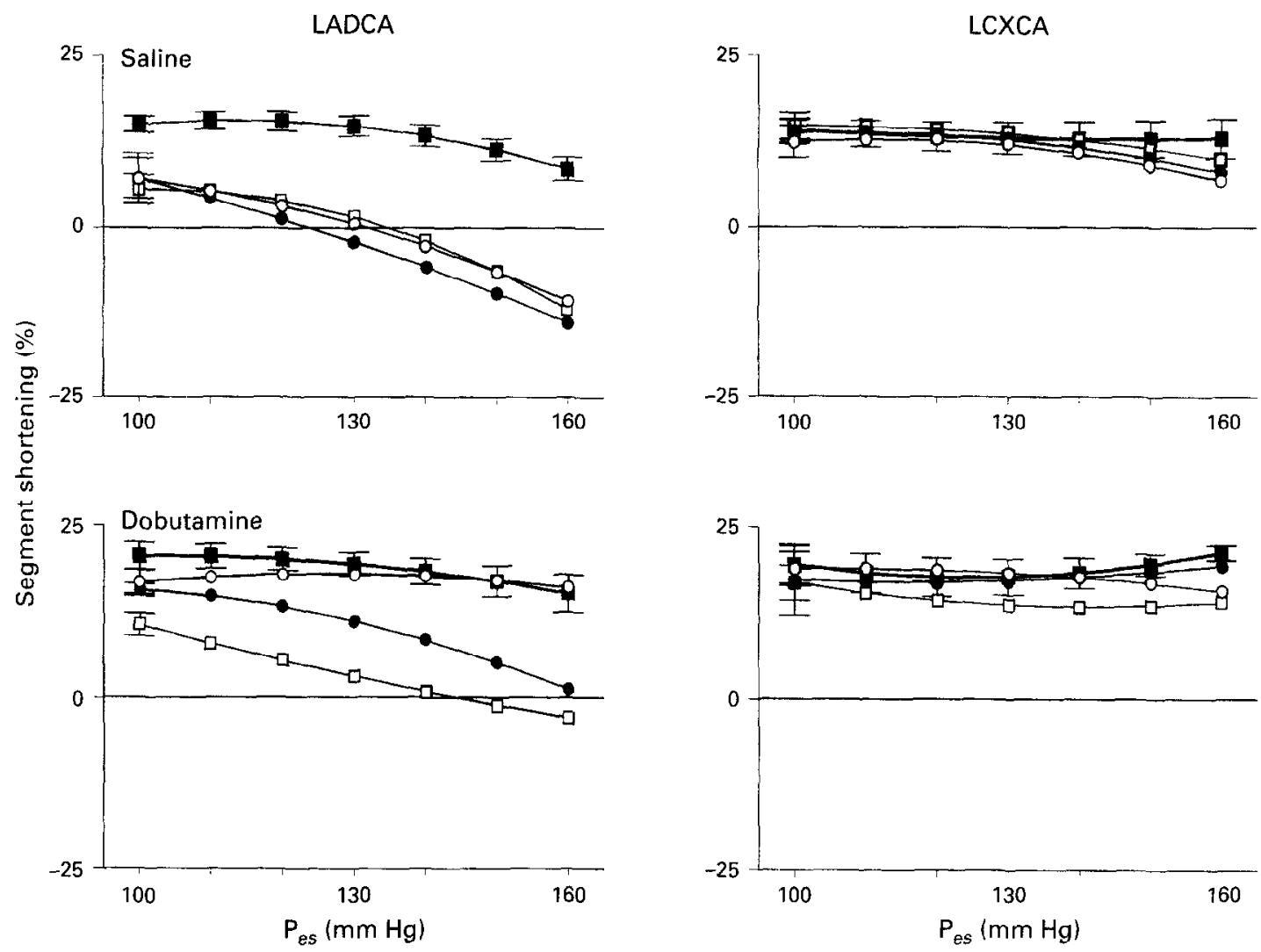

Figure 3 Effect of dobutamine on the afterload dependency of systolic segment shortening of stunned myocardium [left anterior descending coronary artery (LADCA) supplied] and non-stunned myocardium [left circumflex coronary artery (LCXCA) supplied]. Data were obtained at baseline ( $\mathbf{\square})$, after stunning ( $\square)$, and after subsequent infusion of saline $\left(\mathbf{O}=1 \mathrm{ml} \cdot \mathrm{min}^{-1}, O=2 \mathrm{ml} \cdot \mathrm{min}^{-1}\right.$, top panels) or dobutamine $\left(-1 \mu \mathrm{g} \cdot \mathrm{kg}^{-1} \cdot \mathrm{min}^{-1}\right.$ and $\mathrm{O}=3 \mu \mathrm{g} \cdot \mathrm{kg}^{-1} \cdot \mathrm{min}^{-1}$, bottom panels). For the sake of clarity the bars indicating the SEM have only been given in a limited number of data points.

attenuated during infusion of dobutamine. In the distribution area of the left circumflex coronary artery, segment shortening remained insensitive to changes in $\mathrm{P}_{\mathrm{es}}$ during the entire protocol.

Before stunning, $E_{\mathrm{es}}$ decreased as $\mathrm{P}_{\mathrm{cs}}$ increased. During stunning, the dependency of $E_{e s}$ on $P_{e s}$ was decreased as the end systolic pressure-segment length relationship became more linear. During the highest infusion rate of dobutamine the dependency of $E_{s s}$ on $P_{e s}$ was not different from baseline.

\section{Afterload dependency of total mechanical work, external work, and energy conversion efficiency (figs 4-6)}

Before induction of stunning, there was a positive relationship between total mechanical work and $P_{\mathrm{es}}$ in the distribution area of the left anterior descending coronary artery. This relationship was not altered by the stunning protocol and the subsequent infusions of dobutamine (fig 4). External work, on the other hand, showed a similar pattern as segment shortening (compare figs 3 and 5). Consequently energy conversion efficiency became inversely related to $P_{e s}$ after the induction of stunning (fig 6). The lowest dose of dobutamine had only a negligible effect on this inverse relationship, but during infusion of $3 \mu \mathrm{g} \cdot \mathrm{kg}{ }^{1} \cdot \mathrm{min}^{1}$ of dobutamine the relationship normalised (fig 6). The afterload dependency of the energy conversion cfficiency of the nonstunned myocardium was not affected by dobutamine.

Afterload dependency of $\mathrm{EW} / \mathrm{MVO} \mathrm{O}_{2}$ before and after stunning (fig 7)

Before induction of stunning, the afterload dependency of $\mathrm{MVO}_{2}$ could be described, with $\mathrm{MVO}_{2}=0.0274(0.0078)$ $\mathrm{E}_{\mathrm{es}}\left(\mathrm{P}_{\mathrm{es}}\right)+0.0089(0.002)$ PLA $\left(\mathrm{P}_{\mathrm{es}}\right)-0.7043(0.8444)$, in which $\alpha, \beta$, and $\gamma$ were obtained using the data from the pacing tests. After the induction of stunning, this relationship became $\mathrm{MVO}_{2}=0.0275(0.0143) \quad \mathrm{E}_{\mathrm{es}}\left(\mathrm{P}_{\mathrm{es}}\right)+0.0049(0.0014)$ PLA $\left(\mathrm{P}_{\mathrm{e}_{\mathrm{j}}}\right)+1.1447(0.6098)$. Using the dependency of external work, $E_{c s}$, and total mechanical work on $P_{e s}$, we determined the afterload dependency of $E W / \mathrm{MVO}_{2}$ before and after induction of stunning. Figure 7 shows that after induction of stunning $\mathrm{EW} / \mathrm{MVO}_{2}$ decreased as $\mathrm{P}_{\mathrm{es}}$ was increased. For example, EW/MVO 2 decreased only from 55 to $51 \mathrm{~mm} \mathrm{Hg} \cdot \mathrm{mm} \cdot\left(\mu \mathrm{mol} \cdot \text { beat }^{-1} \cdot 100 \mathrm{~g}^{-1}\right)^{-1}$ as $\mathrm{P}_{\mathrm{es}}$ was increased from 100 to $160 \mathrm{~mm} \mathrm{Hg}$ before induction of stunning, but from 48 to $-3 \mathrm{~mm} \mathrm{Hg} \cdot \mathrm{mm} \cdot\left(\mu \text { mol.beat }{ }^{1} \cdot 100 \mathrm{~g}^{1}\right)^{\prime}$ after induction of stunning. Similarly, energy conversion cfficicncy decreased only from $67(3) \%$ to $59(5) \%$ before, but from $57(5) \%$ to $-7(5) \%$ after induction of stunning. Since $\mathrm{PLA} / \mathrm{MVO}_{2}$ was not affected by the stunning protocol, it appears that the increased afterload dependency of $\mathrm{EW} / \mathrm{MVO}_{2}$ during stunning was predominantly determined by the increased afterload dependency of the energy conversion efficiency. Figure 7 also shows that the decrease in EW/MVO $\mathrm{MV}_{2}$ would have been $35 \%$ if $\mathrm{P}_{\mathrm{es}}$ had remained unchanged after induction of stunning, but owing to the decrease in $\mathrm{P}_{\mathrm{es}}$, the decrease in $\mathrm{EW} / \mathrm{MVO}_{2}$ was only $20 \%$.

\section{Discussion}

The decrease in segment shortening in the present study is similar to that reported in an earlier study using the same protocol. $^{4}$ In addition, the end systolic pressure-systolic length relationship rotated clockwise in stunned myocardium and its curvature decreased, which indicates a decrease in contractility. ${ }^{14-16}$ Because of this curvature, we assessed 
LADCA

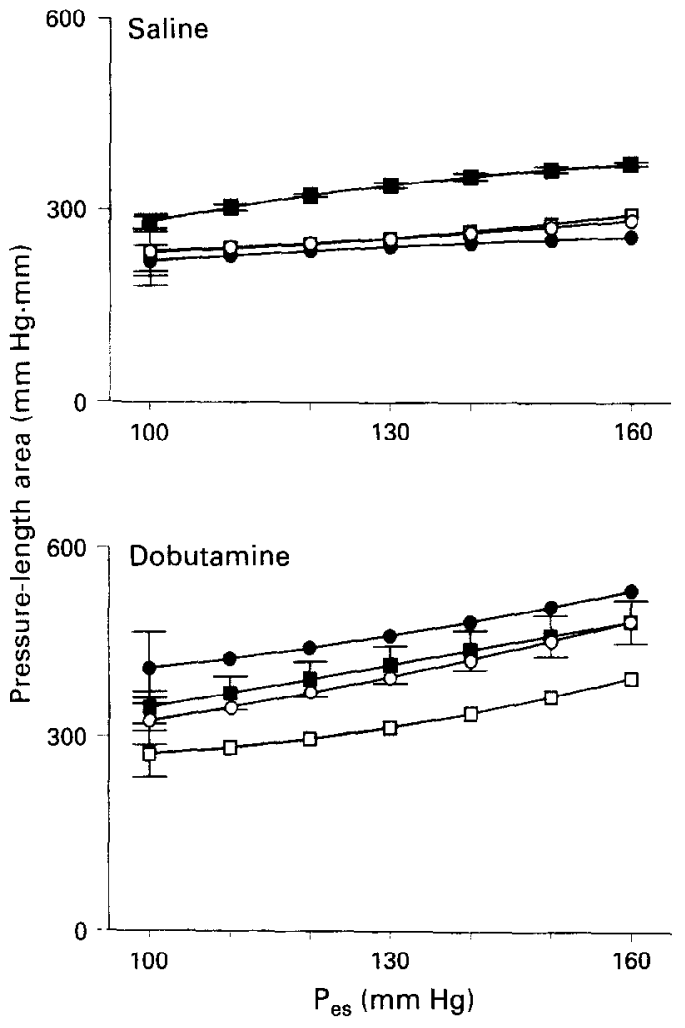

LCXCA
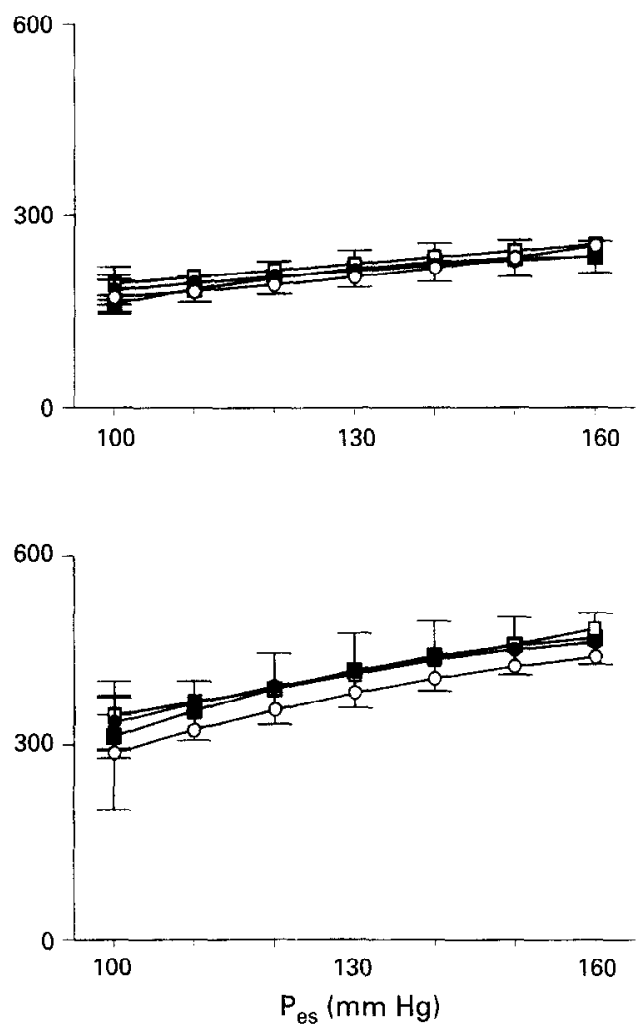

Figure 4 Effect of doubtamine on the afterload dependency of total pressure-length area of stunned (LADCA) and non-stunned (LCXCA) myocardium. See legend of fig 3 for further details.

contractility at $P_{e s}$ values of 100,130 , and $160 \mathrm{~mm} \mathrm{Hg}$ and observed decreases in the slope of the pressure-length relationship of $40 \%, 30 \%$, and $20 \%$, respectively, which also agrees with our earlier findings. ${ }^{4}$ In concert with these

LADCA

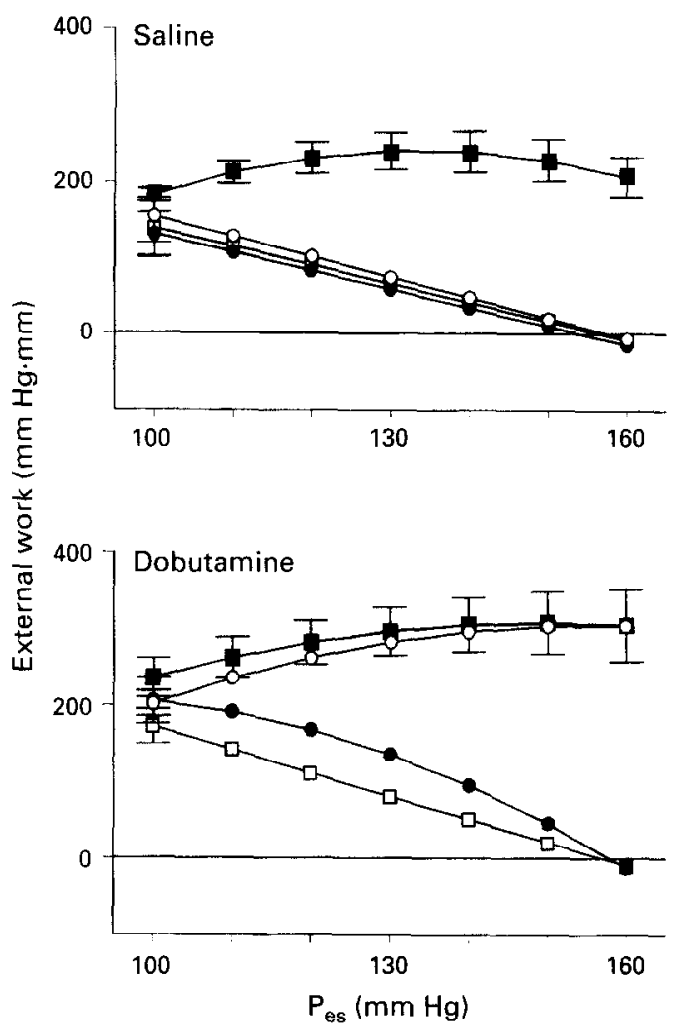

findings, external work decreased. Since total mechanical work remained unchanged, a larger fraction of the consumed oxygen must have been used for conversion of energy into heat. The effect on mechanical efficiency is complicated by
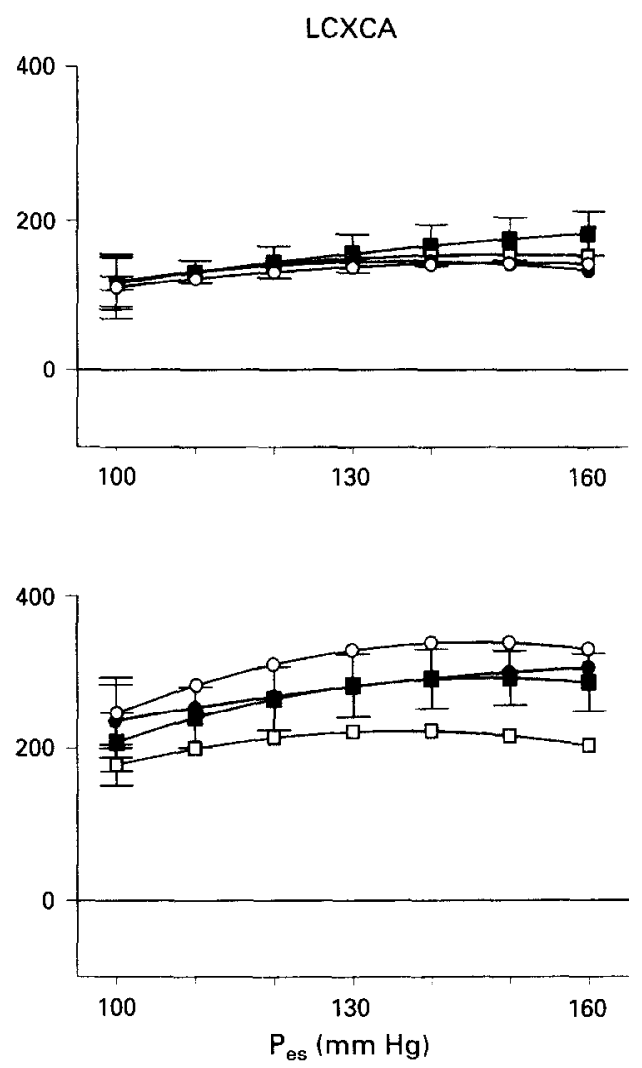

Figure 5 Effect of dobutamine on the afterload dependency of external work of stunned (LADCA) and non-stunned (LCXCA) myocardium. See legend of fig 3 for further details. 

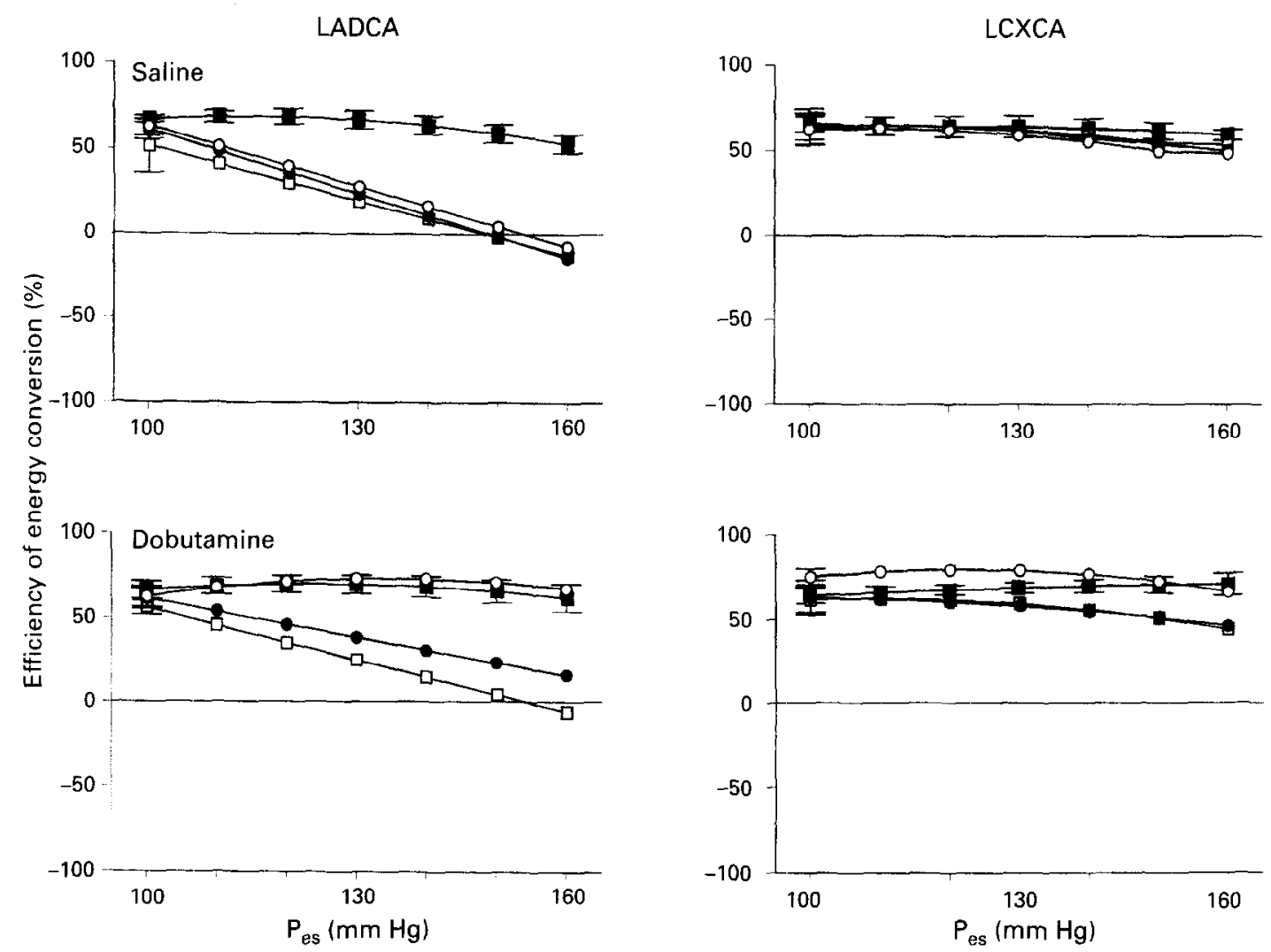

Figure 6 Effect of dobutamine on the afterload dependency of the efficiency of energy conversion (=EW/PLA) of stunned (LADCA) and non-stunned ( $L C X C A)$ myocardium. See legend of fig 3 for further details.

the fact that at constant afterload external work depends on $\mathrm{E}_{\mathrm{es}}$, while oxygen consumption depends on both total mechanical work and $E_{\mathrm{es}}$. A decrease in $E_{\text {es }}$ therefore decreases both external work and oxygen consumption and the relative magnitudes of both effects determine the change in mechanical efficiency. In addition, afterload or end systolic pressure is an important modulator of external work and oxygen consumption and therefore of mechanical efficiency. ${ }^{6} 8$

Segment shortening was relatively insensitive to transient changes in afterload before induction of stunning, but decreased markedly when the afterload was increased after the myocardium was stunned. This increased sensitivity may be an important factor to explain the reported variability regarding the degree of stunning, as it now appears that the depression in segment shortening does not depend only on the species but is also affected by the changes in afterload. ${ }^{6}$ For instance, more severe ischaemia will not only lead to a larger depression in segment shortening, but also to a larger depression in afterload. This larger depression in afterload will, however, oppose the larger decrease in segment shortening. Furthermore, although external work depends on both left ventricular pressure and segment shortening, the increased afterload dependency of external work is mainly due to the increased afterload dependency of segment shortening (compare figs 3 and 5).

The total mechanical work remained relatively insensitive to changes in afterload after induction of stunning. Therefore energy conversion efficiency, which expresses the partitioning of total mechanical work into potential energy and external work, became highly sensitive to changes in afterload after stunning, which is in accordance with the observations of Nozawa ct $a l^{7}$ who showed that the afterload dependency of the energy conversion efficiency was less when myocardial contractility was increased. The attenuation of the afterload dependency of energy conversion efficiency after stimulation with dobutamine further confirmed that contractility is an important modulator of the afterload dependency of energy conversion, as well as external work and segment shortening.

The reported data on myocardial oxygen consumption of stunned myocardium show a large scatter as it has been found to be decreased,,$^{3-5} 1218$ 24-27 unchanged, $^{3}$ and even increased ${ }^{19-23} 28$ compared to its prestunning value. Combining these data with the simultaneously determined regional function data (systolic segment shortening or wall thickening), reveals that the oxygen cost of stunned myocardium is high and that this was more pronounced in pig hearts than in dog hearts. ${ }^{3}$ This postulation has been challenged by Vinten-Johansen et al, ${ }^{5}$ who used the area inside the left ventricular pressure-segment length relationship as an index of external work and demonstrated a decrease in mechanical efficiency of stunned canine myocardium, while Krams et $a l^{4}$ observed a non-significant change in mechanical efficiency of stunned porcine myocardium. These observations ${ }^{45}$ appear to contradict the postulate that species differences play an important role in the variability of mechanical efficiency of stunned myocardium. The hypothesis that the increased afterload dependency of stunned myocardium contributes to the scatter in data on mechanical efficiency was strengthened when the relationship described in fig 7 was tested against published data. ${ }^{4-28}$ Figure 8 shows that, as Schaper et $a l^{3}$ suggested, the decrease in mechanical efficiency was indeed more pronounced in dog than in pig myocardium. However, the decreases in mechanical efficiency proved also to be closely related to the more pronounced stunning induced reductions in arterial pressure or afterload in the pig than in the dog. As shown above, the latter will counteract larger decreases in mechanical efficiency. One factor in the larger stunning 

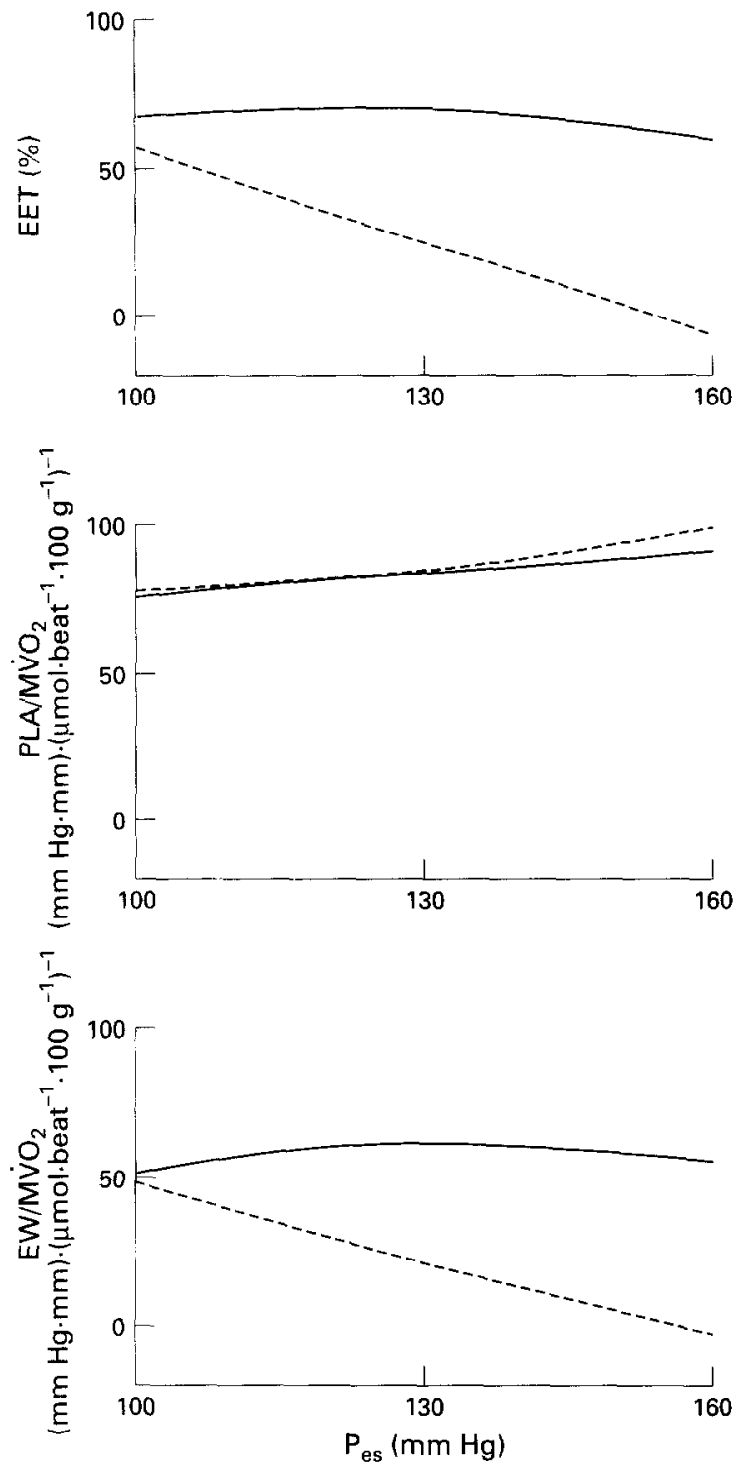

Figure 7 Afterload dependency of mechanical efficiency $\left(E \mathrm{~W} / \mathrm{MVO}_{2}\right)$ before (-) and after (..-) induction of stunning is shown in the bottom panel. The middle panel shows that the afterload dependency of $\mathrm{PLA} / \mathrm{MVO} \mathrm{O}_{2}$ was not changed by the stunning protocol. The afterload dependency of mechanical efficiency after induction of stunning was therefore primarily caused by the increased afterload dependency of energy conversion efficiency (EET) (top panel).

induced decrease in left ventricular end systolic pressure in the pig than in the dog relates to the fact that in the pig the left anterior descending coronary artery supplies a larger fraction of the left ventricular myocardium than in the dog. Another factor is the absence of a coronary collateral circulation in the pig. This larger depression in left ventricular systolic pressure will, because of the increased aftcrload dependency, countcract the decreases in external work and mechanical efficiency. The data in fig 8 show a significant relationship between mechanical efficiency and $\mathrm{P}_{\mathrm{es}}\left(\mathrm{r}^{2}=0.56, \mathrm{P}<0.05\right)$, implying that $56 \%$ of the variability in mechanical efficiency could be explained by the changes in $\mathrm{P}_{\mathrm{es}}$. The remaining variability suggests that other factors such as duration of preceding ischaemia, sequences of the occlusion-reperfusion protocols, anaesthesia, and temperature may play an additional role. For instance Triana et $a l^{29}$ have shown that both wall thickening (and therefore also segment shortening) and oxygen consumption of stunned myocardium depend upon body temperature. How-
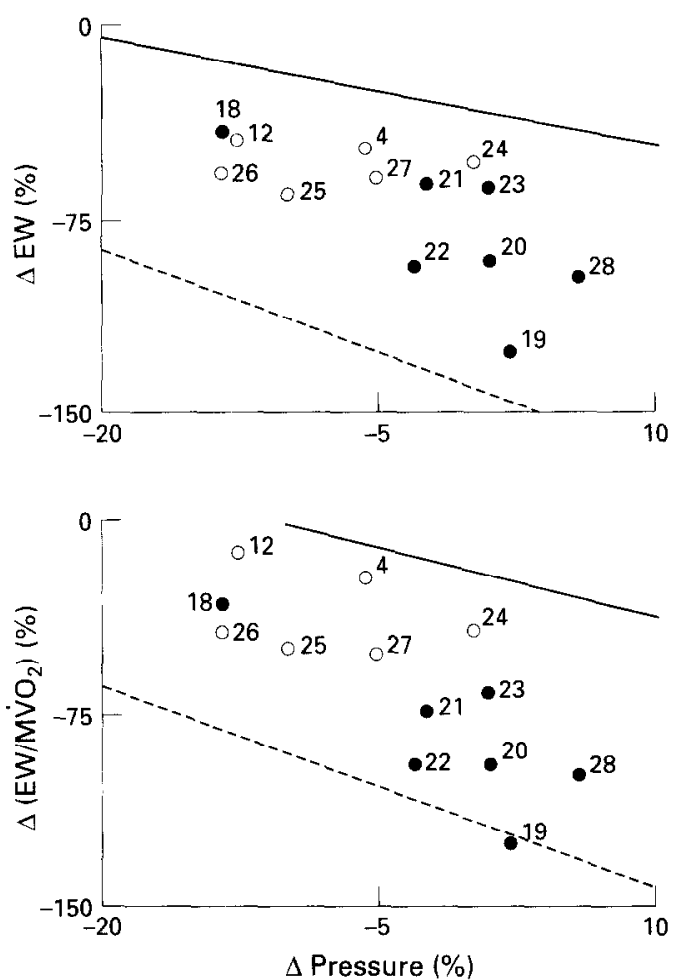

Figure 8 Dependency of external work (upper panel) and mechanical efficiency (lower panel) on changes in pressure induced by stunning obtained from the present study and compared with data $(r=0.68,0.75$ respectively; $:$ dog, $0:$ pig) collected from published reports (numbers refer to references). The lines were the relationships derived from fig 5 and fig 7 at end systolic pressures of $\left(P_{e s}\right)$ of $100 \mathrm{~mm} \mathrm{Hg}(-)$ and $160 \mathrm{~mm} \mathrm{Hg}(\ldots)$. There was a difference of mechanical efficiency between pig and dog; this was mainly due to different decreases in pressure.

ever, in the present study we controlled the body temperature of the animals between 37 and $38^{\circ} \mathrm{C}$, a range in which the wall thickening is less temperature dependent. ${ }^{29}$

Further analysis showed that since the ratio of total mechanical work over oxygen consumption (PLA/MVOO ${ }_{2}$ ) remained almost unchanged, the afterload dependency of mechanical efficiency was predominantly determined by the pronounced afterload dependency of energy conversion efficiency during stunning (fig 7). Inotropic stimulation with dobutamine not only restored the steady state values of mechanical efficiency, external work, and energy conversion efficiency (table III; fig 2) to baseline, but also attenuated the afterload dependency of energy conversion efficiency. Since in the present experiments, the afterload dependency of mechanical efficiency is primarily determined by the afterload dependency of energy conversion efficiency, our results indirectly indicate that the increased afterload sensitivity of mechanical efficiency might also be a consequence of the decreasc in $E_{e s}$, which reflects disturbances in excitationcontraction coupling. Disturbances in excitation-contraction coupling have been related to a diminished calcium cycling or decreased myofibrillar calcium sensitivity or both. The present report does not discriminate between these two mechanisms, but earlier studies from our laboratory have shown that at the time points in which we determined the depressed segment shortening, external work and $E_{e s}$ of the postischaemic myocardium, the activity of the calcium pump of the sarcoplasmic reticulum is normal ${ }^{30}$ and that administration of a calcium sensitiser specifically increases mechanical efficiency of the stunned region. ${ }^{27}$ 


\section{Limitations of the method}

Myocardial oxygen consumption data contain information about the entire myocardial wall, and wall thickening may therefore be a more appropriate functional variable as segment shortening and derived indices such as external work and $\mathrm{E}_{\mathrm{es}}$ characterise the function of the layers in which the crystals are implanted. We have earlier shown, however, that in pigs crystals implanted in the subendocardial and subepicardial layers of normal and reperfused myocardium respond similarly to inotropic stimuli. ${ }^{31}$

Left ventricular end systolic pressure was used as an index of afterload but other indices such as aortic input impedance have also becn proposed. The latter not only incorporates vascular resistance, but also vascular compliance and inertia, ${ }^{32}$ and can not therefore be characterised with a single number. Others have defined force per cross sectional area (stress or pressure) as an index of afterload. As regional stress depends on the regional curvature, which was not determined during this experiment, end systolic pressure has been adopted, despite its shortcomings, in the present study as a single index of afterload.

After induction of stunning the curvature of the end systolic pressure-systolic length relationship was close to zero, which implies that $E_{e s}$ became independent of $P_{e s}$. This linear relationship is most certainly caused by the experimental conditions such as duration and severity of the ischaemic periods and the time of measurement, and should therefore not be considered to be a fundamental property of the stunned myocardium. It is in agreement, however, with measurements obtained from studies in isolated heart. ${ }^{14}$

Finally for heart rates less than 100 beats $\mathrm{min}^{-1}, \gamma$ is heart rate dependent. ${ }^{33}$ In the present study heart rates was consistently higher than 100 beats $\mathrm{min}^{-1}$, a range in which the effect of heart rate on $\gamma$ becomes negligible. ${ }^{33}$

\section{Conclusion}

In conclusion, we examined the changes in segment shortening, external work, mechanical efficiency, and energy conversion efficiency during transient changes in afterload before and after induction of myocardial stunning. The results show that the afterload dependency of segment shortening, external work, mechanical efficiency, and energy conversion efficiency became much more pronounced in stunned myocardium, and this could be reversed by dobutamine infusion. These findings therefore imply that the disturbances in energy conversion in stunned myocardium become highly afterload dependent, due to a decrease of contractility, resulting in a decreased mechanical efficiency at physiological afterloads. The stunning induced decrease in afterload, however, tends to oppose the decrease in mechanical efficiency induced by the decrease in contractility. These opposing factors explain the reported variability of external work and mechanical efficiency of stunned myocardium.

This study was supported by grant 92.308 from the Netherlands Heart Foundation.

Key terms: myocardial stunning; efficiency of energy conversion; afterload; end systolic pressure-segment length relationships; dobutamine; pig.

Received 3 August 1994; accepted 31 October 1994. Time for primary review 21 days.

1 Schipke JD. Cardiac efficiency. Basic Res Cardiol 1994;89: $207-40$.
2 Zimmer SD, Bache RJ. Metabolic correlates of reversibly injured myocardium: myocardial oxygen consumption and carbon substrate utilization. In: Kloner RA, Przyklenk K, eds. Stunned myocardium: properties, mechanics and clinical manifestations. New York: Marcel Dekker, 1993:41-70.

3 Schaper W, Schott RJ, Kobayashi M. Reperfused myocardium: stunning, preconditioning, and reperfusion injury. In: Heusch G, ed. Pathophysiology and rational pharmacotherapy of myocardial ischemia. New York: Springer, 1990:175-97.

4 Krams R, Duncker DJ, McFalls EO, Hogendoorn A, Verdouw PD. Dobutamine restores the reduced efficiency of energy transfer from total mechanical work to external mechanical work in stunned porcine myocardium. Cardiovasc Res 1993;27:740-7.

5 Vinten-Johansen J, Gayheart PA, Johnston WE, Julian JS, Cordell AR. Regional function, blood flow, and oxygen utilization relations in repetitively occluded-reperfused canine myocardium. Am J Physiol 1991:261(Heart Circ Physiol 30):H538-47.

6 Suga H. Ventricular energetics. Physiol Rev 1990;70:247-77.

7 Nozawa $T$, Yasumura Y, Futaki S, Tanaka N, Uenishia M, Suga $H$. Efficiency of energy transfer from pressure-volume area to external mechanical work increases with contractile state and decreases with afterload in the left ventricle of anaesthetized closed-chest dogs. Circulation 1988;77:1116-24.

8 Burkhoff D, Sagawa K. Ventricular efficiency predicted by an analytical model. Am J Physiol 1986;250(Regul Integrative Comp Physiol 19):R1021-7.

9 Bien J, Sharaf B, Gewirtz H. Origin of anterior interventricular vein blood in domestic swine. Am J Physiol 1991;260 (Heart Circ Physiol 29):H1732-6.

10 Streeter DD, Spotnitz HM, Patel DP, Ross J, Sonnenblick EH. Fiber orientation in the canine left ventricle during diastole and systole. Circ Res 1969;24:339-47.

11 Aversano T, Maughan WL, Hunter WC, Kass D, Becker LC. End systolic measures of regional ventricular performance. Circulation 1986:73:938-50.

12 Schott RJ, Rohmann S, Braun ER, Schaper W. Ischemic preconditioning reduces infarct size in swine myocardium. Circ Res 1990;66:1133-42

13 Van der Welden EP, Burkhoff D, Steendijk P, Kansdon J Sagawa K, Baan J. Nonlinearity and load sensitivity of end-systolic pressure-volume relation of canine left ventricle. Circulation 1991:83:315-27.

14 Burkhoff D, Sugiura S, Yue D, Sagawa K. Contractility-dependent curvilinearity of end-systolic pressure-volume relations. $A m J$ Physiol 1987;252(Heart Circ Physiol 21):H1218-27.

15 Kass DA, Beyar R, Lankford E, Heard M, Maughan WL Sagawa K. Influence of contractile state on curvilinearity of in situ cnd-systolic pressure-volume relations. Circulation 1989; 79: $167-78$.

16 Noda T, Cheng CP, De Tombe PP, Little WC. Curvilearity of LV end-sysiolic pressure-volume and $\mathrm{dP} / \mathrm{dt}_{\max }$ end-diastolic volume relations. Am J Physiol 1993;265(Heart Circ Physiol 34):H910-7.

17 Morris JJ, Pellan GL, Murphy CE, Salter DR, Goldstein JP, Wechsler AS. Quantification of the contractile response to injury: assessment of the work-length relationship in the intact heart Circulation 1987;76:717-27.

18 Chiu WC, Kedem J, Scholz PM, Weiss HR. Regional asynchrony of segment contraction may explain the "oxygen consumption paradox" in stunned myocardium. Basic Res Cardiol 1994;89: 149-62.

19 Dean EN, Shlafer M, Nicklas JM. The oxygen consumption paradox of "stunned myocardium" in dogs. Basic Res Cardiol 1990;85:120-31

20 Ehring T, Bohm M, Heusch G. The calcium antagonist nisoldipine improves the functional recovery of reperfused myocardium only when given before ischemia. J Cardiovasc Pharmacol 1992;20: 63-74.

21 Farber N, Pieper GM, Gross GJ. Postischemic recovery in the stunned myocardium after reperfusion in the presence or absence of a flow-limiting coronary artery stenosis. Am Heart $J$ 1988; 116:407-20.

22 Kawashima S, Satani A, Tsumoto S, et al. Coronary pressure-flow, pressure-function, and function-myocardial oxygen consumption relations in postischaemic myocardium. Cardiovasc Res 1991;25: $837-43$

23 Laxson DD, Homans DC, Dai X, Sublett E, Bache RJ. Oxygen consumption and coronary reactivity in postischemic myocardium. Circ Res 1989;64:9-20.

24 Liedtke AJ, DeMaison L, Eggleston AM, Cohen LM, Nellis SH. Changes in substrate metabolism and effects of excess fatty acids in reperfused myocardium. Circ Res 1988;62:535-42.

25 McFalls EO, Duncker DJ, Krams R, Sassen LMA, Hogendoorn A, Verdouw PD. The recruitment of myocardial work and metabolism in regionally stunned porcine myocardium. Am J Physiol 1992; 263(Heart Circ Physiol 32):H1724-3I. 
26 Schulz R, Janssen F, Guth BD, Heusch G. Effect of coronary hyperperfusion on regional myocardial function and oxygen consumption of stunned myocardium in pigs. Basic Res Cardiol 1991;86:534-43.

27 Soei LK. Sassen LMA, Fan DS, Van Veen T, Krams R, Verdouw $\mathrm{PD}$. Myofibrillar $\mathrm{Ca}^{++}$sensitization predominantly enhances function and mechanical efficiency of stunned myocardium. Circulation 1994;90:959-68.

28 Stahl LD, Weiss HR, Becker LC. Myocardial oxygen consumption, oxygen supply/demand heterogeneity, and microvascular patency in regionally stunned myocardium. Circulation 1988;77:865-72

29 Triana JF, Li XY, Jamaluddin U, Thornby JI, Bolli R. Postischemic myocardial "stunning": identification of major differences between the open-chest and the conscious dog and evaluation of the oxygen radical hypothesis in the conscious dog. Circ Res 1991;69:731-47.

30 Lamers JMJ, Duncker DJ, Bezstarosti K, McFalls EO, Sassen LMA, Verdouw PD. Increased activity of sarcoplasmic reticular calcium transport in porcine stunned myocardium. Cardiovasc Res 1993;27:520-4

31 Sassen LMA, Dunker DJGM, Gho BCG, Diekmann HW, Verdouw PD. Haemodynamic profile of the potassium channel activator EMD 52692 in anaesthetized pigs. Br J Pharmacol 1990;101:605-14.

32 Milnor WR. Arterial impedance as ventricular afterload. Circ Res 1975;36:565-70.

33 Harasawa Y, De Tombe PP, Sheriff DD, Hunter WC. Basal metabolism adds a significant offset to unloaded myocardial oxygen consumption per minute. Circ Res 1992;71:414-22.

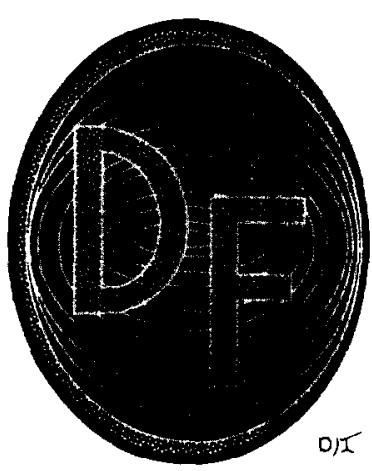

